\title{
LIII. The direct measurement of the Peltier effect
}

\section{F.W. Jordan A.R.C.S. B.Sc.}

To cite this article: F.W. Jordan A.R.C.S. B.Sc. (1911) LIII. The direct measurement of the Peltier effect, Philosophical Magazine Series 6, 21:124, 454-464, DOI: $10.1080 / 14786440408637053$

To link to this article: http://dx.doi.org/10.1080/14786440408637053

$$
\text { 册 Published online: } 21 \text { Apr } 2009 .
$$

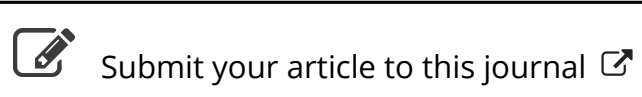

\footnotetext{
Џll Article views: 7
}

Q View related articles $\asymp$

4 Citing articles: 5 View citing articles 
The experimental results obtained show, however, that there is practically no difference in the intensities for the two gases, which proves that the bombardment theory is quite untenable.

In conclusion my best thanks are due to Professor Barkla for his interest and encouragement during the carrying out of these experiments.

Wheatstone Laboratory, King's College.

LIII. The Direct Measurement of the Peltier Iffect. By F. W. Jordan, A.R.C.S., B.Se.*

TTHE Peltier coefficient may be measured directly by the calorimetric methods of Le Roux $\dagger$ and Jahn $\neq$, or it may be deduced from the thermoelectric power by using the thermodynamic relation

$$
\mathrm{P}=\mathrm{T} \frac{d \mathrm{E}}{d \mathrm{~T}},
$$

where $\mathrm{P}=$ Peltier coefficient, and $\frac{d \mathrm{E}}{d \mathrm{~T}}=$ the thermoelectric power at the absolute tempe-

The methods of Le Roux and Jahn are tedious, and can ouly be applied when one of the junctions is isolated thermally from the other. The apparatus deseribed in this paper was designed in 1909 for the direct measurement of the Peltier coefficient between copper and a short specimen of crystallized bismuth in the limited space between the poles of an electromagnet. Pellat $\$$, in 1901, suggested a somewhat similar method, but he does not appear to have made an experiment to test its accuracy. He discnsses the case of a compound bar of iron and zine traversed by a current of 20 amperes in such a direction that heat is absorbed at the junction. $\mathrm{H}_{\theta}$ suggested that the Peltier absorption of heat might be compensated by the heat evolved by a current through a fine insulated wire embedded in the iron close to the junction. The l'eltier effect will produce in each bar a temperature

* Communicated by the Author.

+ Le Roux, Ann. de Chimie et de Phys. i. p. 201 (1867).

f H. Jahn, Wied. Ann. xxxiv. p. $75 \overline{0}$ (1888).

$\$$ Pellat, Comptes Rendus, cxxxiii. p. 921 (1901). 
gradient towards the junction, and therefore, to compensate this, the current through the fine wire would be adjusted so that the temperature gradient, as indicated by insulated thermojunctions, vanishes in each bar. The Joule effects in the bar and leads $4 \mathrm{~mm}$. thick were considered to be negligible, and to have no disturbing effect on the temperature gradients in the bar.

If $I=$ the current through the bar,

$i=$ the current throngh the heating coil,

$e=$ the potential difference at terminals of heating coil. Then

$$
\mathrm{PI}=e i .
$$

At the ordinary temperature of the air, the heat evolved per cm. length of the iron lead is approximately one-third of the heat absorbed at the junction for a current of 20 amperes, and therefore the neglect of the Joule effect is scarcely justifiable. The dimensions of the apparatus are linge for an experiment in a limited space, and owing to the large thermal capacity of the bar a considerable interval would be required before the steady state and the final adjustment of the compensating current were attained.

In the following method the two junctions of the copper with the bismuth could not be isolated, and the apparatus is equivalent to a duplication of Pellat's arrangement with many subsequent advantages.

If a current be sent round a circnit of two metals, then the temperature difference between the junctions, arising from the Peltier effects, can be made to vanish by a continuous supply of heat to the cooler junction. In the ideal case, when the junctions are equal in all respects, the rate at which heat must be supplied to the cooler junction is equal to twice that at which it is evolved at the warmer junction. The thermal conductivity of copper is much greater than that of bismuth, and therefore it is preferable to supply the heat by the passage of a current through an insulated fine wire embedded in the copper close to each junction. The presence of a heating coil at each junction renders it possible to eliminate from the final result the electrical resistances and the different thermal emissivities of the junctions. The apparatus was also dimensioned so that, at each junction, the Joule heat for the average current of one ampere was abont one-tenth of the Peltier heat. In the experiments of Jahn with a Bunsen ice-calorimeter the Peltier heat was only a small part of the measured quantity of heat. 
The bismuth rod $e$ was cut from a crystallized mass, prepared by $\mathrm{Dr}$. Lownds, so that its axis was parallel to the principal cleavage plane of the metal. Two copper cylinders $c, d$, were bored out to receive the heating coils, and their

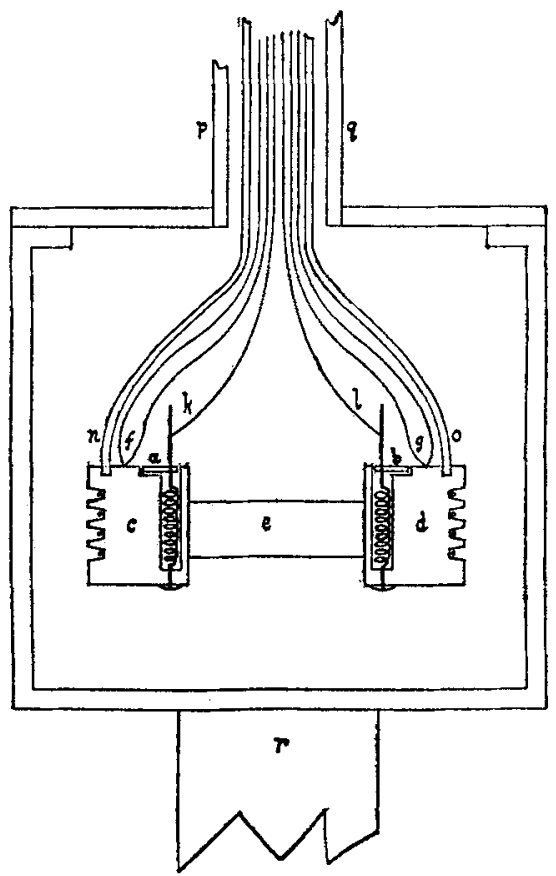

curved surfaces were planed down to within a millimetre of the coils. The end of the bismuth rod was pressed against and fused to the flat surface of the cylinder. After solidification the excess of fused bismuth around the rod was removed. Each heating coil consisted of a spiral of fine double-silk-covered eureka wire, which was soldered at each end to thicker copper wire. The upper copper lead was soldered to a circular copper disk $a$, and the lower one was attached to the cylinder by electroplating with copper. A copper wire $k$ soldered to the upper lead served as a potential lead for measuring the resistance of the coil, and also as a lead for the heating current. The coil and copper disk were insulated from the cylinder by paraffin wax. The object of securing the coil in this way was to maintain as far as possible an equality of temperature between the copper cylinder and the terminals of the coil, and so minimise the loss of heat by conduction along the leads. 
The difference of temperature between the cylinlers was indicated by four thermocouples of copper and constantan wires. These junctions were laid in grooves and insulated from the cylinders by thin strips of miea. The grooves were filled in with cotton-wool, and this together with the junctions was tied to the cylinders with silk thread. The available galvanometer was of the suspended-coil type having a resistance of 45 ohms, a period of abont 10 seconds, and a figure of merit of $350 \mathrm{~mm}$. scale-divisions per microampere. The galvanometer, when connected to the thermo-junctions, gave $n$ deflexion of about $10 \mathrm{~mm}$. per 0.01 ampere from one cylinder to the other.

The difference of temperature between the copper-bismuth junctions may also be observed by interrupting the currents through the rod and heating coil and connecting the coppers with the galvanometer. Stray thermoelectric forces in the use of this method would be relatively more important since the thermoelectric power of this junction is only abont onethird of that of the four copper-constantan cumples. This method would be suitable with a galvanometer of low resistance and short period. The temperature of each cylinder was measured by a copper-constantan junction $f, g$, soldered to the copper.

The various leads were insulated from one another in glass tubes and passed throngh a copper tube, $p q$, which was soldered to the coyer of the enclosure. The constant-temperature enclosure was a small rectangular copper vessel with walls $2 \mathrm{~mm}$. thick. This was designed for the small gap between the poles of an electromagnet, and in this position the temperature could be reduced by immersing the copper rod extension $r$ in ice and water.

The currents through the junctions and the heating coil were both sent through the same copper lead, $n, o$, and therefore, if necessary, could he easily intermpted simultaneously. The cnrrents were supplied from two separate batteries of accumulators and could be varied almost independently. Each of these currents could be measured to about 1 part in 500 by moving coil ammeters.

In making an experiment the current through the heating coil was kept constant, and that through the junctions was adjusted so that the thermo-junctions gave a small steady deflexion. The exact compensating current through the junctions was deduced from the change of deflexion of the galvanometer, produced by a small change of current through the junctions. Since both the currents traverse the same copper lead to cylinder, it is necessary to reverse the heating

Phil. Mag. S. 6. Vol. 21. No. 124. April 1911. $2 \mathrm{H}$ 
current through the coil in order to eliminate its Joule effect in the lead. This was done, and the mean compensating current through the junctions was observed. The unequal emissivities of the two copper cylinders were eliminated by reversing the current through the junctions and passing the heating current tbrough the other coil.

To obtain the temperature of each junction, one of the thermo-junctions $f$ was connected in series with another and the galvanometer. 'Ihe second junction was immersed in water, and this was warmed until the galvanometer was undeflected. The temperature of the water, as read on a thermometer, was then the temperature of the copper cylinder and each junction.

The compensating current through the junctions was also determined by using the copper-bismuth junction as an indicator of the temperature difference between the cylinders. It was found that, in the two methods, the compensating currents differed by 0005 ampere approximately for a given heating current. It follows that the insulated thermocouples could be relied upon to indicate the temperature difference between the cylinders.

It is assumed, in calculating the Peltier coefficient, that the temperature of each copper cylinder is practically uniform throughout, and that possible Peltier and Thomson effects external to the surface of contact are negligible. There is no doubt that the fusing of the bismuth rod to the copper damages the crystalline structure at the end of the rod, and so produces a thin transition layer through which the Peltier effect is distributed. The sum of the Peltier effects across this thin layer is measured in this experiment, and according to the laws of the thermoelectric circuit this total Peltier effect is equal to the Peltier effect between the copper and the crystallized bismuth.

Let $Q=$ rate of supply of energy by lieating coil ;

$\mathrm{C}=$ mean compensating current through junctions for a given current in one heating coil ;

$\mathrm{P}=$ Peltier coefficient;

$r=$ effective resistance of the metals about a junction ;

$k=$ rate of loss of energy from a copper cylinder per degree excess of temperature above the enclosure;

$t=$ excess of temperature of each cylinder above the enclosure.

Then the following equations hold for a current $C_{1}$ through 
the junctions during the steady state :

$$
\begin{aligned}
& \mathrm{Q}_{1}+\mathrm{C}_{1}^{2} r_{1}-\mathrm{PC}_{1}=k_{1} t_{1} \text {.... } \\
& \mathrm{C}_{1}^{2} r_{2}+\mathrm{PC}_{1}=k_{2} t_{1} \text {. . . . }
\end{aligned}
$$

and for a reversed current $\mathrm{C}_{2}$ :

$$
\begin{aligned}
& \mathrm{C}_{2}{ }^{2} r_{1}+\mathrm{PC}_{2}=k_{1} t_{2} \text {. . . . } \\
& \mathrm{Q}_{2}+\mathrm{C}_{2}^{2} r_{2}-\mathrm{PC}_{2}=k_{2} t_{2} \text {. . . . . }
\end{aligned}
$$

These equations give

$$
\mathrm{P}=\frac{k_{2} \mathrm{Q}_{1}+k_{1} \mathrm{Q}_{2}}{\left(\mathrm{C}_{1}+\left(\mathrm{C}_{2}\right)\left(k_{1}+k_{2}\right)\right.}+\left(\mathrm{C}_{1}-\mathrm{C}_{2}\right)\left\{\left(\frac{k_{1}-k_{2}}{k_{1}+k_{2}}\right) r_{1}+\frac{k_{1}}{k_{1}+k_{2}}\left(r_{2}-r_{1}\right)\right\} \text {. }
$$

In the experiment $Q_{1}$ was made nearly equal to $Q_{2}$. In this case the maximum value of the second term, as deducerl from the observations, was about 0.001 of the first term, and is thorefore negligible. The second term may be made to vanish by making $\mathrm{C}_{2}=\mathrm{C}_{1}$; but this necessitates an approximate value of the ratio of $k_{1}$ to $k_{2}$ to evaluate the first term.

Thus

$$
\mathrm{P}=\frac{\mathrm{Q}_{1}+\mathrm{Q}_{2}}{2\left(\mathrm{C}_{1}+\mathrm{C}_{2}\right)} \cdot \text {. . . . . . }
$$

The tables below contain some of the results of experiments

\begin{tabular}{|c|c|c|c|c|}
\hline $\begin{array}{l}\text { Heating } \\
\text { Current. }\end{array}$ & $\begin{array}{l}\text { Junction } \\
\text { Current. }\end{array}$ & $\begin{array}{l}\text { Mean Temp. } \\
\text { of junction. }\end{array}$ & $\begin{array}{l}\text { Peltier } \\
\text { Coefficient. }\end{array}$ & $\begin{array}{c}\text { Thermoeloctric } \\
\text { Pown. }\end{array}$ \\
\hline $\begin{array}{l}a+0 \cdot 125 \text { amp. } \\
a-0 \cdot 125 \\
b+0 \cdot 130 \\
b-0.130\end{array}$ & $\begin{array}{l}c-1.466 \text { amp. } \\
, 1.431 \\
d-1.366 \\
, 1.330\end{array}$ & $22^{\circ} \cdot 4 \mathrm{C}$ & 001590 volt & $53.8 \times 10^{-6}$ volt \\
\hline $\begin{array}{l}a+0.070 \\
a-0.070 \\
b+0.072 \\
b-0.072\end{array}$ & $\begin{array}{r}c-0.461 \\
0.455 \\
d-0.426 \\
,, 0.411\end{array}$ & $20^{\circ} \cdot 6$ & 0.01573 volt & $53.6 \times 10^{-6}$ volt \\
\hline $\begin{array}{l}a+0 \cdot 100 \\
a \rightarrow 0 \cdot 100 \\
b+0 \cdot 102 \\
b-0 \cdot 102\end{array}$ & $\begin{array}{r}c-1.040 \\
.1 .018 \\
d-0.892 \\
, 0.868\end{array}$ & $8^{\circ} \cdot 1$ & 0.01462 rolt & $52.0 \times 10^{-6}$ volt \\
\hline
\end{tabular}
with different currents and at slightly different temperatures. The thermoelectric powers of the copper-bismuth junction as calculated from the relation

are also given.

$$
\mathbf{P}=\mathrm{T} \frac{d \mathrm{E}}{d \mathrm{~T}}
$$

The resistance of coil $a=2 \cdot 780$ ohms.

$$
" \quad \Rightarrow \quad b=2 \cdot 692 \quad "
$$


As an instance of the calculation of $\mathrm{P}:-$ At $22^{\circ} \cdot 4 \mathrm{C}$,

$$
\begin{aligned}
& \mathrm{P}=\frac{0 \cdot 125^{2} \times 2 \cdot 78+0 \cdot 130^{2} \times 2 \cdot 692}{1 \cdot 466+1.431+1.366+1.332} \\
& \mathrm{P}=0.01590 \text { volt from bismuth to copper. }
\end{aligned}
$$

In this ense the excess of temperature of cylinder above enclosure $=3^{\circ}$ nearly.

The resistance of the bismuth rod between copper cylinders $=1730 \times 10^{-6} \mathrm{olnm}$.

$$
\text { Length of rod }=1.76 \mathrm{~cm} \text {. }
$$

Mean cross-sectional area of rod $=0 \cdot 154 \mathrm{sq} . \mathrm{cm}$.

Specific resistance at $19^{\circ} \cdot 5=151 \times 10^{-6} \mathrm{ohm}$.

The effective resistance of the copper lead to cylinder was deduced from the change of the compensating current through the junction on reversing the current through the heating coil.

Let $C_{1}$ and $C_{2}$ be the values of the junction currents;

c the current through the heating coil;

$r_{3}$ the effective resistance of the copper lead which is traversed by both the junction and heating currents;

$r_{t}$ the effective resistance of the bismuth rod at this junction;

$x_{2}$ the total effective resistance of the copper lead and bismuth rod at the other junction.

Then the following equations hold for currents $\mathrm{C}_{1}$ and $e$ in the same direction through the copper lead:-

$$
\begin{aligned}
& \mathrm{Q}+\left(\mathrm{C}_{1}+c\right)^{2} r_{3}+\mathrm{C}_{1}^{2} r_{4}-\mathrm{PC}_{1}=k_{1} t_{1} \quad . \quad . . \\
& \mathrm{C}_{1}^{2} r_{2}+\mathrm{PC}_{1}=k_{2} t_{1} . \quad . \quad .
\end{aligned}
$$

and for a reversed current $c$ :-

$$
\begin{array}{r}
\mathrm{Q}+\left(\mathrm{C}_{2}-c\right)^{2} r_{3}+\mathrm{C}_{2}^{2} r_{4}-\mathrm{PC}_{2}=k_{1} t_{2} \\
\mathrm{C}_{2}^{2} r_{2}+\mathrm{PC}_{2}=k_{2} t_{2}
\end{array}
$$

These equations give

$$
\begin{array}{r}
r_{3}\left(\mathrm{C}-\mathrm{C}_{2}+2 c\right)\left(\mathrm{C}_{1}+\mathrm{C}_{2}\right)=\frac{k_{1}+k_{2}}{l_{2}}\left\{r_{2}\left(\mathrm{C}_{1}^{2}-\mathrm{C}_{2}^{2}\right)+\mathrm{P}\left(\mathrm{C}_{1}-\mathrm{C}_{2}\right)\right\} \\
-\left(r_{4}+r_{2}\right)\left(\mathrm{C}_{1}^{2}-\mathrm{C}_{2}^{2}\right) .
\end{array}
$$

To obtain an approximate value of $r_{3}, \frac{k_{1}+k_{2}}{k_{2}}$ may be written $=2$; and since the results in the table show that the 
effective resistances of the two junctions are nearly the same, $r_{2}$ may be written $=r_{3}+r_{4}$. Then

$$
r_{3}=\frac{\mathrm{P}\left(\mathrm{C}_{1}-\mathrm{C}_{2}\right)}{c\left(\mathrm{C}_{1}+\mathrm{C}_{2}^{-}\right)} \cdot \cdot \cdot \cdot \cdot .
$$

Taking the results from the first part of the table,

$$
\begin{aligned}
& r_{3}=\frac{0.0159 \times 0.035}{0.125 \times 2.9} \\
& r_{3}=0.0015 \mathrm{ohm} \text { nearly. }
\end{aligned}
$$

The maximum possible resistance of each junction will be $r_{3}$ together with half the resistance of the bismuth rod.

In the complete equation for $\mathrm{P}(5)$,

$$
r_{1}=r_{2}=0.0015+00009=0.0024 \mathrm{ohm} \text { nearly. }
$$

The approximate value of $\frac{k_{1}}{k_{2}}$ as obtained by substitution in (1) and (2) is 1.08. Substituting these values in equation (5) the second term

$$
\begin{aligned}
& \left(\mathrm{C}_{2}-\mathrm{C}_{1}\right)\left\{\left(\frac{k_{1}-k_{2}}{k_{1}+k_{2}}\right) r_{1}+\frac{k_{1}}{k_{1}+k_{2}}\left(r_{2}-r_{1}\right)\right\} \\
& =-(1 \cdot 45-1 \cdot 35)\left\{\left(\frac{1 \cdot 08-1}{1 \cdot 08}\right) 0.0024+0\right\} \\
& =-9 \cdot 2 \times 10^{-6} \text { volt nearly. }
\end{aligned}
$$

Since $\mathrm{P}=15900 \times 10^{-6}$ volt by equation ( 6$)$, it follows that the second term in (5) is much less than the errors of observation and can be neglected. Thus the calculation of $P$ by equation (6) is correct to 1 part in 1000 , even when $Q_{2}$ differs from $Q_{1}$ by 4 per cent. When errors of observation are taken into account the final result is probably correct to 1 part in 200 , and this order of accuracy was uimed at in designing the apparatus.

The bismuth, which was supplied by Griffin and known as Kahlbaum's pure bismuth, was carefully crystallized by Dr. Lownds in the following way. A crucible was overwound with a coil of eureka wire and surrounded on all sides with sand and asbestos. About 1000 gms. of bismuth were melted in the covered crucible, and the whole mass was very slowly cooled by gradually diminishing the current through the coil. The whole operation of cooling lasted 36 hours. The crucible was broken and the lump of bismuth remored. A blow with a hammer near the upper edge 
divided the lump along a plane inclined to the axis of figure of the crystallized mass. The brilliant surfaces of cleavage could be traced by chipping and eutting to the middle of the lump, and were found to be nearly plane and parallel to each other. The rod of bismuth in this experiment was cut from the middle of the crystallized mass so that its axis was parallel to the principal cleavage plane of the bismuth. The surfaces of contact of the bismath rod with the copper were at right angles to the principal cleavage planes.

This method of preparing the specimen of crystallized bis. muth is, with the exception of the electrical heating, similar to that employed by Perrot*. He prepared several crystals from the same mass of bismuth and measured for each the thermoelectric power with copper in two different positions. In one of these positions, the surfaces of contact with the copper were parallel to the principal cleavage plane of the crystal, and in the other position they were at right angles to this plane. The first of these positions was designated by the symbol $I 1$ and the second by the symbol $\perp$. He found that the thermoelectric power in the position II was a pproximately twice as great as in position $\perp$ at a temperature of $55^{\circ}(\%$ The thermoelectric powers at a temperature of $55^{\circ} \mathrm{C}$. for four of his crystals in position $\perp$ are given here for the purpose of comparison with the value derived from the Peltier coefficients in the table above.

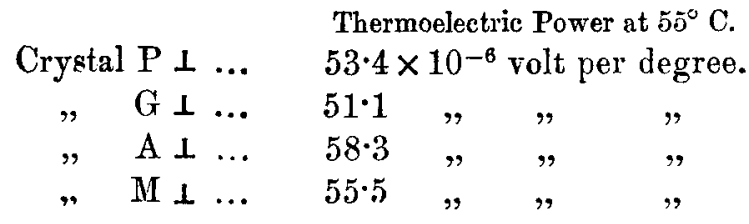

The lengths of these crystals varied from $19 \mathrm{~mm}$. to $30 \mathrm{~mm}$. In the table above the thermoelectric power as derived from the Peltier coefficient would at $55^{\circ} \mathrm{C}$. be equal to $57 \cdot 6 \times 10^{-6}$ volt per degree. Considering the widely different results that Perrot obtained, this value is quite acceptable. The bismuth used by Perrot was analysed by three chemists and found to be pure, with the exception of an undetermined trace of iron. The different results obtained by him are probably due to slight irregularities in the structure of the crystals. The bismuth rod in this apparatus has not yet been analysed, and consequently no accurate comparison of the results can be made.

* F. L. Perrot, Arch. des Scicnces Phys. et Nat. Aug. 1898. 
In Perrot's experiments a large temperature-gradient was established between the two contret surfaces, and the thermoelectric power would include possible thermoelectric forces arising from sliwht changes in the crystalline structure. In the apparatus, described in this paper, the mean of the Peltier forces near the ends of the crystallized rod is measured. and therefore the derived value of the thermoelectric power might differ from that of Perrot's. Differences, arising from impurities in the bismuth rod, are also possible.

To apply this method to the measurement of the Peltier coefficient for any two metals, the copper leads $n, o$ would be replaced by one metal and the bismuth rod e by the other metal. To dissipate the Joule effect and to reduce the effective resistance of each junction, it is preferable to take each metal in the form of a thin strip. Wach strip should be approximately dimensioned so that the total flow of heat per unit temperature-gradient is the same as for the bismuth rod. In this case the resistance of the junction would be much less than that of the copper-bismuth junction in this apparatus. An additional lead for the current through each heating coil must be soldered to each copper cylinder. The same sensibility can be attained, in the case of small Peltier effects, by increasing the number of thermo-junctions attached to each cylinder, and also by reducing the size of the copper cylinders. 'This modified apparatus would be suitable in the case where only a short length of one of the metals was available. The Peltier effect could also be measured at various temperatures by varying the tomperature of the enclosure.

An attempt was made to measure the thermoelectric power of the copper-bismuth junction by passing a current through one of the coils and measuring the E.M.F. of the junctions. The temperature difference thus produced between the junctions was small and could not be measured with sufficient accuracy owing to a defective attachment of the junctions $f, g$. One junction of the two wires projected about $1 \mathrm{~mm}$. from the cylinder, and although the other appeared to be satisfactory the results showed that this was slightly defective. Owing to the brittleness of the bismuth rod, these defects were not remedied. The following results indicate the existence of these defects.

$$
\text { At } 22^{\circ} \cdot 5 \text { C. } \frac{d \mathrm{E}}{d t}=64.8 \times 10^{-6} \text { volt per degree, }
$$

with faulty junction at the higher temperature. 
When the tempcraturc-difference was reversed,

$$
\frac{d \mathrm{E}}{d t}=56 \cdot 3 \times 10^{-6} \text { volt per degree, }
$$

with faulty junction at the lower temperature.

The fault of the junction arose from the temperature gradient along the wires $(0.1 \mathrm{~mm}$. diam.). This conld be remedied by soldering a junction of thinner wires in a groove and winding the insulated leads around the cylinder, in order to minimize the temperature gradient. A junction was attached in this way to a similar copper cylinder. The defective junction and the insulated junction were also imitated approximately. The latter was laid in a groove and separated from the cylinder by a thin strip of mica $0.02 \mathrm{~mm}$. thick. The rest of the groove was packed with cotton-wool and overwound with silk thread. The cylinder was heated electrically inside a copper enclosure, and the following results were obtained:-

Excess temperature of cylinder over enclosure $=8^{\circ}$ nearly. $\left.\begin{array}{c}\text { Temperature difference between the perfect } \\ \text { and defective junctions ..................... }\end{array}\right\}=0^{\circ} \cdot 25 \mathrm{C}$.

The temperature difference between the perfect and insulated junction varied from $0^{\circ} \cdot 3$ to $0^{\circ} \cdot 45$, according to tho tightness of the filling of cotton-wool in the groove.

The results indicate the precautions that must be taken in fixing the thermo-junctions to the cylinder for this particular measurement. It is to be noted that this slight defect in tho junctions $f^{\prime}, g$ will not disturb the temperatures in the third column of the table by more than $0^{\circ} \cdot 1$. The high results for the direct measurement of the thermoelectric power are just what are to be expected when the junctions are faulty and the rod is a short one.

It is interded to conduct experiments with this apparatus in a magnetic field to determine how the Peltier coefficient depends on the strength and direction of the field across the surface of contact of the bismuth with the copper.

South-Westem Polyteclinic, Chelsea, S.W. September 18, 1910 . 